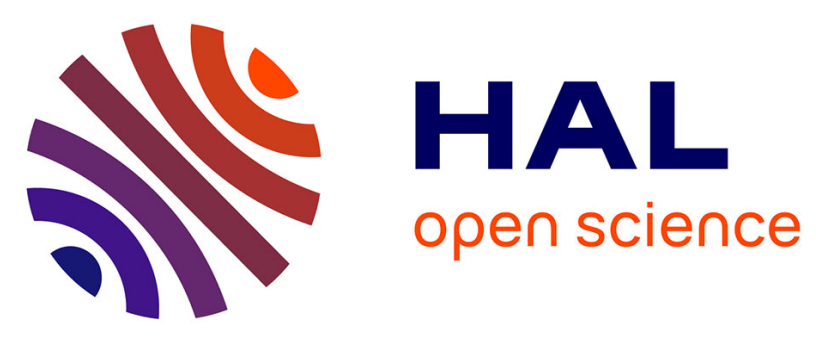

\title{
Investigating the pore-water chemistry effects on the volume change behaviour of Boom clay
}

\author{
Yongfeng Deng, Yu-Jun Cui, Anh Minh A.M. Tang, Xuan-Phu Nguyen,
} Xiang-Ling Li, Maarten van Geet

\section{- To cite this version:}

Yongfeng Deng, Yu-Jun Cui, Anh Minh A.M. Tang, Xuan-Phu Nguyen, Xiang-Ling Li, et al.. Investigating the pore-water chemistry effects on the volume change behaviour of Boom clay. Physics and Chemistry of The Earth, 2011, 36 (17-18), pp.1905-1912. 10.1016/j.pce.2011.07.016 . hal-00655753

\section{HAL Id: hal-00655753}

https://hal-enpc.archives-ouvertes.fr/hal-00655753

Submitted on 2 Jan 2012

HAL is a multi-disciplinary open access archive for the deposit and dissemination of scientific research documents, whether they are published or not. The documents may come from teaching and research institutions in France or abroad, or from public or private research centers.
L'archive ouverte pluridisciplinaire HAL, est destinée au dépôt et à la diffusion de documents scientifiques de niveau recherche, publiés ou non, émanant des établissements d'enseignement et de recherche français ou étrangers, des laboratoires publics ou privés. 


\title{
Investigating the pore-water chemistry effects on the volume change behaviour of Boom clay
}

\author{
Y. F. Deng ${ }^{1,2}$, Y. J. Cui' ${ }^{2}$ A. M. Tang', X. P. Nguyen², X. L. Li ${ }^{3}$, V.G. Maarten ${ }^{4}$ \\ ${ }^{1}$ Southeast University, Institute of Geotechnical Engineering, Transportation College, Nanjing, \\ China (noden@163.com) \\ ${ }^{2}$ Ecole des Ponts ParisTech, Navier/CERMES, Marne-la-Vallée, France (yujun.cui@enpc.fr) \\ ${ }^{3}$ Euridice Group, c/o SCK/CEN, Mol, Belgium (xli@ sckcen.be) \\ ${ }^{4}$ ONDRAF/NIRAS, Belgium (mvgeet@sckcen.be)
}

\section{Corresponding author}

Prof. Yu-Jun CUI

Ecole des Ponts ParisTech, Navier/CERMES

6-8 av. Blaise Pascal, Cité Descartes, Champs-sur-Marne

F-77455 MARNE-LA-VALLEE CEDEX 2

France

Email: yujun.cui@enpc.fr

Tel: +33164153550

Fax: +33164153562 


\begin{abstract}
The Essen site has been chosen as an alternative site for nuclear waste disposal in Belgium. The soil formation involved at this site is the same as at Mol site: Boom clay. However, owing to its geographical situation closer to the sea, Boom clay at Essen presents a pore water salinity 4-5 times higher than Boom clay at Mol. This study aims at studying the effects of pore water salinity on the hydro-mechanical behaviour of Boom clay. Specific oedometer cells were used allowing "flushing" the pore water in soil specimen by synthetic pore water or distilled water. The synthetic pore water used was prepared with the chemistry as that for the site water: $5.037 \mathrm{~g} / \mathrm{L}$ for core Ess83 and $5.578 \mathrm{~g} / \mathrm{L}$ for core Ess96. Mechanical loading was then carried out on the soil specimen after flushing. The results show that water salinity effect on the liquid limit is negligible. The saturation or pore water replacement under the in situ stress of $2.4 \mathrm{MPa}$ does not induce significant volume change. For Ess83, hydro-mechanical behaviour was found to be slightly influenced by the water salinity; on the contrary, no obvious effect was identified on the hydro-mechanical behaviour of Ess96. This can be attributed to the higher smectite content in Ess83 than in Ess96.
\end{abstract}

Keywords: Boom clay; pore water salinity; volume change behavior, oedometer tests. 


\section{Introduction}

In the Belgian program for nuclear waste disposal, the Essen site has been considered as an alternative site to the relatively well-known Mol site (Bernier et al., 2007; Cui et al., 2009). The Essen site is located in the north-east of Belgium, about $60 \mathrm{~km}$ far from Mol (Figure 1, De Craen et al., 2006). As it is closer to the sea than the Mol site, the Boom clay involved presents a pore water salinity 4-5 times higher than that at Mol (De Craen et al., 2006). To the authors' knowledge, the effect of this high pore water salinity on the hydro-mechanical behaviour of Boom clay has not been investigated yet. Nevertheless, for other clays, numerous studies have been reported in the literature about the effect of pore-water chemistry on the hydromechanical behaviour (Bowders and Daniel, 1986; Waddah and Mohammed, 1997; Di Maio, 1996, Di Miao et al., 2004; Chen and Anandarajah, 1998; Sridharan and Prakash, 1999; Kaya and Fang, 2000; Sridharan et al., 2002; Ören and Kaya, 2003; Wakim, 2005; Gajo and Maines, 2007; Yukselen-Aksoy et al., 2008; Simile, 2008). These studies showed that inorganic salt solutions have a strong impact on the hydro-mechanical behaviour of clays, especially on swelling clays. Examination of the test conditions applied in these studied shows that it is difficult to extend the results to Boom clay. Indeed, most tests were carried out on either soil slurries or remould soils. The salinity was applied to the soil either before the sample preparation by mixing soils powder with the studied solution or after the sample preparation by putting the sample in the salinity environment (Wakim, 2005). Obviously, when studying the pore-water chemistry effect on Boom clay, the salinity methods for slurries and remould clays are not applicable as it is not allowed to destroy the initial microstructure of the soil. On the other hand, the method used by Wakim (2005) is believed to not be efficient because the fully saturation of soil sample by the desired pore water of different salinity can be suspected when simply putting the sample in the pore water.

In the present work, to ensure the full replacement of pore water with the soil sample, a "flushing" method was applied that allows the desired water to percolate the soil sample. Synthetic pore water that has the same chemistry as the site water was used. Distilled water was also used to make a comparison. Note that the range of water chemistry considered was not large since the total salinity of pore water at Essen site is between 5.037 and $5.578 \mathrm{~g} / \mathrm{L}$. The liquid limit $\mathrm{w}_{\mathrm{L}}$ of Boom clay at Essen was were first analysed with both synthetic pore water and distilled water. Afterwards, a special oedometer was set up to replace soil pore water with either synthetic pore water or distilled water. Loading and unloading paths were then applied to study the hydro-mechanical behaviour under different salinity conditions.

\section{Materials and methods}

The soil cores studied were taken from the borehole drilled in Essen at the depth of 226.65$227.65 \mathrm{~m}$ (Ess83) within the Putte member, and at the depth of 239.62-240.62 m (Ess96) within the Terhagen member. The cores have a dimension of $1.0 \mathrm{~m}$ in length and $100 \mathrm{~mm}$ in diameter. They were sealed in plastic tubes with ends closed for water loss prevention, and transported to the laboratory for testing.

Table 1 shows the chemical composition of pore-water of cores Ess83 and Ess96 (De Craen et al., 2006) and that of Boom clay at Mol (Cui et al. 2009). The results show that the pore-water at Essen contains $\mathrm{NaHCO}_{3}, \mathrm{Na}_{2} \mathrm{SO}_{4}, \mathrm{KCl}, \mathrm{CaCl}_{2} \cdot 2 \mathrm{H}_{2} \mathrm{O}, \mathrm{MgCl}_{2} \cdot \mathrm{H}_{2} \mathrm{O}$ and $\mathrm{NaCl}$, and $\mathrm{NaCl}$ being the main salt. The pore-water taken from $\mathrm{Mol}$ contains $\mathrm{NaHCO}_{3}, \mathrm{Na}_{2} \mathrm{SO}_{4}, \mathrm{KCl}, \mathrm{MgCl}_{2} .2 \mathrm{H}_{2} \mathrm{O}$, 
$\mathrm{NaCl}, \mathrm{H}_{3} \mathrm{BO}_{3}, \mathrm{NaF}$ and $\mathrm{CaCO}_{3}$, and $\mathrm{NaHCO}_{3}$ being the main salt. Comparison between the values for Ess83 and Ess96 shows that there is few difference between the two cores. The total salinity of the pore-water at Essen site is $5.037-5.578 \mathrm{~g} / \mathrm{L}$, while that at Mol site is only 1.286 $\mathrm{g} / \mathrm{L}$. The results also showed that the main cation at both sites is $\mathrm{Na}^{+}$, with a concentration of $0.072-0.080 \mathrm{Mol} / \mathrm{L}$ at Essen and $0.014 \mathrm{Mol} / \mathrm{L}$ at Mol, i.e., $5-6$ times lower. Note that the salinity of seawater usually ranges from 3.3 to $3.7 \%$ in weight; indicating that the salinity of pore water at Essen is about 1.5 times higher as that of seawater, while that at Mol is about 2 times lower than that of seawater.

The geotechnical properties of these two cores that were determined using distilled water are shown in Table 2. It can be observed that Ess 83 and Ess 96 present similar properties: a specific gravity $G_{s}=2.64$ against 2.68; a liquid limit $w_{L}=67.2$ against $67.1 \%$; a plastic limit $w_{P}=33 \%$ for both; a plastic index $I_{P}=37$ against 36; a soil water content $w=27.2$ against $26.5 \%$; a void ratio $e=0.730$ against 0.715 ; a blue methylene value $\mathrm{VBS}=6.67$ against 6.20 ; a carbonate content of 7.6 against $2.4 \mathrm{~g} / \mathrm{kg}$. The liquid limit values were also determined using Essen synthetic water (prepared with the same chemistry as for the site water) and slightly higher values were obtained: $w_{L}=69.6$ for Ess83 and $w_{L}=68.9$ for Ess96. The difference in $w_{L}$ between the case of distilled water and the case of synthetic water is rather related to the test accuracy, and can be neglected. Yukselen-Aksoy et al. (2008) analysed the results from the literature on several clays and observed also a neglected effect of high salinity water (seawater) when $\mathrm{w}_{\mathrm{L}}$ is lower than $110 \%$. For high plasticity clay, lower $\mathrm{w}_{\mathrm{L}}$ values have been obtained with high salinity water (Cajo and Maines, 2007; Yukselen-Aksoy et al. 2008).

The particle size distribution curves of the two cores are shown in Figure 2. It is observed that the two curves are quite close, especially in the coarse particles part $(>10 \mu \mathrm{m})$ where they overlap. The clay content $(<2 \mu \mathrm{m})$ of Ess96 is about $61 \%$, slightly higher than that of Ess83: $57 \%$.

Table 3 shows the mineralogical composition of the whole soils and the composition of the clay fractions $(<2 \mu \mathrm{m})$, obtained by X-ray diffraction analysis. It is observed that the main minerals of Ess83 are quartz (60\%), illite/mica (10\%) and kaolinite (30\%). Ess96 has a higher quartz content $(70 \%)$ and a lower kaolinite content $(20 \%)$. For the clay fractions, the contents of chlorite, kaolinite and illite are similar for the two soils, but the smectite content of Ess 83 is higher than that of Ess96: 20\% against 10\%.

In order to investigate the salinity effect on the hydro-mechanical behaviour of Boom clay, in this study, oedometer tests were conducted on soil samples $(50 \mathrm{~mm}$ in diameter and $20 \mathrm{~mm}$ high) prepared by trimming with both synthetic water and distilled water. A controller of pressure/volume (CPV) was used for water injection. The hydraulic conductivity, oedometer modulus, primary consolidation coefficient and secondary consolidation coefficient were determined from the tests and then compared. In total, four tests were performed, two with synthetic water (Ess83Odo3, Ess960do04) and two with distilled water (Ess83Odo4, Ess960do05). 


\section{Experimental results}

The results of one typical test (Ess83Odo3 with synthetic water) are shown in Figure 3. After installation of the soil sample in the oedometer cell, a loading cycle $(0.05 \mathrm{MPa}$ to $2.4 \mathrm{MPa}$, 2.4 $\mathrm{MPa}$ to $0.05 \mathrm{MPa}$, and $0.05 \mathrm{MPa}$ to $2.4 \mathrm{MPa}$ ) was applied in order to ensure the good contact between the sample, porous stone and cell. Note that this cycle would eliminate the effects of possible soil disturbance due to the transport, conservation and sample preparation. The French standard (AFNOR, 1995, 2005) was used for the deformation stability criterion: the deformation was considered as stabilised when it was lower than $0.01 \mathrm{~mm} / \mathrm{h}$. Note also that the value of $2.4 \mathrm{MPa}$ corresponds to the in situ stress. Actually, by considering a mean unit weight of $20 \mathrm{kN} / \mathrm{m}^{3}$ for the soils above the depth considered (De Craen et al., 2006) and a ground water level assumed to be at the ground surface, the in situ effective stress was estimated at 2.27 MPa for Ess83 and 2.4 MPa for Ess96. For a reason of experimental convenience, the initial vertical effective stress $\sigma_{v}^{\prime}$ was set at $2.40 \mathrm{MPa}$ for both Ess83 and Ess96. The application of this in situ stress was performed prior to saturating the sample, in order to prevent the soil swelling which may modify the soil microstructure and as a consequence the soil mechanical properties (Delage et al., 2007).

For the sample saturation or pore water replacement, a pressure $\mathrm{P}_{\mathrm{CPV}}$ of $1.0 \mathrm{MPa}$ was applied through the lower base, injecting the desired water to the soil sample. When the volume of water injected was more than 4 times of the soil porosity (see $d_{V_{C P V}}$ in Figure 3), the sample was considered as fully saturated with the water injected. Afterwards, the pressure was then decreased to $10 \mathrm{kPa}$ prior to the further loading/unloading steps. It was observed that the saturation phase did not induce significant change in soil volume (see the displacement Disp in Figure 3), indicating that i) the vertical stress of $2.4 \mathrm{MPa}$ is indeed quite close to the in situ stress, and ii) the chemistry of synthetic water is well representative of the chemistry of the in situ pore water. Note that the volume of water flow through the soil specimen allowed determination of the hydraulic conductivity following the Darcy's law.

In order to study the compressibility behaviour after the water saturation phase, the sample was unloaded from 2.4 MPa (I) to $0.05 \mathrm{MPa}$ (II), loaded to 3.2 MPa (III), re-unloaded 0.05 MPa (IV) (Figure 3). Again, the French standard (AFNOR, 1995, 2005) was applied to judge the deformation stabilisation under each load: the last deformation should be lower than $0.01 \mathrm{~mm} / 8 \mathrm{~h}$. The displacement determined at the end of each loading step allowed determination of the corresponding void ratio. In Figure 4 the void ratio is plotted versus the vertical effective stress for test Ess83Odo3. It is observed that the first loading step $\left(\sigma_{\mathrm{v}}\right.$ increases from 0.1 to $2.4 \mathrm{MPa}$ ) induced only a small change in void ratio. The subsequent unloading and reloading paths did not result in negligible volume change. As mentioned above, the saturation under the in situ stress $\left(\sigma^{\prime}{ }_{\mathrm{v}}=2.4 \mathrm{MPa}\right)$ did not induce any change in void ratio. After the saturation phase, unloading from $\sigma_{\mathrm{v}}=2.4 \mathrm{MPa}$ (I) to $0.05 \mathrm{MPa}$ (II) induced significant swelling; the void ratio increased from 0.62 to 0.88 . During the loading path from $\sigma^{\prime}{ }_{\mathrm{v}}=0.05 \mathrm{MPa}$ (II) to $3.2 \mathrm{MPa}$ (III), a non linear compression behaviour was observed. The unloading path from $\sigma^{\prime}{ }_{\mathrm{v}}=3.2 \mathrm{MPa}$ (III) to $0.05 \mathrm{MPa}$ (IV) is similar to the first unloading path (from I to II).

For further analysis on the soil behaviour, only the compression curves obtained after the saturation phase was used (Figure $5 a$ for test Ess83Odo3). These curves allow determination of the compressibility parameters such as the compression index $\left(C^{*}{ }_{c}\right)$, the swelling index $\left(C^{*}{ }_{s}\right)$, and the oedometer modulus $E_{O d o}$ that is defined as:

$E_{\text {Odo }}=h_{i}\left(d \sigma_{v}^{\prime} / d h\right)$ 
Where $h_{i}$ is the initial height of the soil sample; $\mathrm{d} h$ is the height change induced by a vertical stress increment $\mathrm{d} \sigma_{v}{ }^{\prime}$. Because the compression index $C_{c}$ and the swelling index $\mathrm{C}_{\mathrm{s}}$ change significantly from one step to another, in this study, a compression index $C^{*}{ }_{c}$ and a swelling index $C^{*}$ is adopted that corresponds to the values of $C_{c}$ and $\mathrm{C}_{\mathrm{s}}$ at each loading or unloading step.

In Figure $5 b$, the void ratio change versus time is plotted for only one loading step. This consolidation curve allows determination of the consolidation coefficient $c_{v}$ following the Casagrande's method $\left(c_{v}=0.197 H^{2} / t_{50}\right.$, where $H$ is the drainage length equal to the half of the sample height and $t_{50}$ is the time required to reach $50 \%$ consolidation). Using the expression $k$ $=c_{v} \rho_{w} g / E_{O d o}$, the hydraulic conductivity $k$ was then calculated; where $\rho_{w}$ is the density of water and $\mathrm{g}$ is the gravitational acceleration.

Moreover, the curve shown in Figure $5 b$ can be used to determine the secondary deformation coefficient $C_{\alpha}$, that corresponds to the slope -de/dlogt of the line after the part of primary deformation. Hence this definition implies that $C_{\alpha}$ is positive for loading stages as II->III in tests Ess83Odo3, and negative for unloading stages as I->II and III->IV in tests Ess83Odo3.

In Figure 6, the compression curves of all 4 tests (obtained after application of the in situ stress) are shown. Examination of the effect of the pore water replacement shows that quite slight swelling was induced by this process, no matter with synthetic water (Ess83Odo3 and Ess960do4) or distilled water (Ess83Odo4 and Ess960do5). This observation suggests that the swelling behaviour or the swelling pressure of Boom clay is not sensitive to changes in pore water salinity.

As far as the unloading/loading/unloading curves are concerned, all tests show almost a reversible behaviour with a significant hysteresis. When comparing test Ess830do3 with synthetic water and test Ess83Odo4 with distilled water, it is observed that the compression curves are quite similar. The same conclusion can be made when comparing test Ess96Odo4 with synthetic water and test Ess960do5 with distilled water. This suggests a negligible effect of the pore water chemistry on the compression behaviour of Boom clay.

Figure 7 shows the hydraulic conductivity k of Ess83 and Ess96 versus void ratio. For each core, the results obtained with different water (synthetic water or distilled water) and by different methods (the direct method based on the water volume injected by the CPV and the indirect Casagrande's method) are gathered in a same figure for comparison. For Ess83, it can be observed that the measurements of $\mathrm{k}$ by the two methods gave similar results. On the other hand, the water chemistry did not affect the hydraulic conductivity since similar values were obtained with two different pore water salinities. On the whole, a linear relationship is observed between $\mathrm{k}$ and e. For Ess96, a small difference can be identified between test Ess960do4 with synthetic water and test Ess960do5 with distilled water. In addition, a relatively higher value was also obtained in Ess960do5 based on the CPV measurements. These differences are believed to not be significant and can be included in the range of the experimental results scattering. As for Ess83, a linear relationship between k and e was also obtained for ess96.

Figure 8 presents the oedometer modulus $E_{O d o}$ versus the void ratio e during both loading and unloading paths for Ess83 and Ess96 in a semi-logarithmic coordinates. For Ess83, it is observed that for a given stress path, the points from test Ess83Odo4 with distilled water lies slightly below the points from test Ess83Odo3 with synthetic water, suggesting weakening effect of distilled water. However, for Ess96, a good agreement is observed between the points 
from test Ess96Odo5 with distilled water and the points from test Ess96Odo4 with synthetic water.

The results of consolidation coefficient $C_{v}$ are shown in Figure 9. As for the oedometer modulus $E_{O d o}$, the values of $C_{v}$ from test Ess83Odo4 with distilled water are slightly lower than that from test Ess83Odo3 with synthetic water; by contrast, test Ess96Odo5 with distilled water gave quite consistent results when compared to test Ess96Odo4 with synthetic water. The correspondence between $E_{O d o}$ and $C_{v}$ can be easily explained by their determinations. Indeed, $C_{v}$ can be also expressed as $k E_{O d o} /\left(\rho_{w} g\right)$, when k is constant for a given void ratio (see Figure 7), $E_{O d o}$ and $C_{v}$ are directly correlated.

Changes in the secondary deformation coefficient $C_{\alpha}$ with the void ratio $e$ is depicted in Figure 10. For Ess83, the absolute values of $C_{\alpha}$ from test Ess83Odo4 with distilled water are found be to larger than that from test Ess83Odo3 with synthetic water, especially for the unloading paths (I->II and III->IV). By contrast, for Ess96, this phenomenon is not obvious and the curves corresponding to two water chemistries almost overlap.

Figure 11 shows the relationship between the secondary consolidation coefficient $C_{\alpha}$ and the compression index $C{ }^{*}$ or the swelling index $C^{*}{ }_{s}$. A good linear correlation is obtained between $C_{\alpha}$ and $C_{c}{ }^{*}$ for both Ess83 and Ess96: $C_{\alpha}=0.024 C_{c} *$ for Ess83 and $C_{\alpha}=0.023 C_{c} *$ for Ess96. Moreover, no water chemistry effect is observed. This observation shows that the secondary consolidation behaviour of Boom clay is similar to that of shake or mudstone reported by Mesri et al. (1994).

\section{Discussion}

In the low range of pore water salinity considered (between 5.037 and $5.578 \mathrm{~g} / \mathrm{L}$ ), it has been observed that for Ess96 there isn't significant effect of the pore water salinity on the hydraulic conductivity, oedometer modulus, primary consolidation coefficient and secondary consolidation coefficient. By contrast, for Ess83, a low effect was identified on the oedometer modulus, the primary and secondary deformation coefficients: $E_{O d o}$ and $C_{v}$ are larger and $C_{a}$ is lower in case of synthetic water as compared to the case of distilled water. But for both Ess83 and Ess96, the salinity of pore water does not affect the relationship between the hydraulic conductivity and the void ratio. These observations lead to conclude that for Ess83, increasing the pore water salinity accelerates the soil consolidation but reduces its deformation and secondary consolidation.

Comparison of the mineralogical composition between Ess83 and Ess96 (see Table 3) shows that the contents of quartz and clay smectite mineral of Ess83 are $10 \%$ higher than that of Ess96, while the contents of kaolinite and interstratified illite/smectite of Ess 83 are $10 \%$ lower than that of Ess96. Note that kaolinite, quartz and illite are relative stable minerals, while smectite and to a certain extent interstratified illite/smectite are swelling minerals. Furthermore, From Table 1, it is observed that sodium ion $\left(\mathrm{Na}^{+}\right)$was the main cation in pore water, and its concentration is $0.072 \mathrm{M}$ in Ess83 and $0.080 \mathrm{M}$ in Ess96. The concentrations in both cores are low and in addition the difference between two cores is small.

From the mineralogical analysis above, it can be concluded that in the condition of low $\mathrm{Na}^{+}$ concentration, the content of smectite mineral is likely the main factor to be considered when investigating the pore water chemistry effects on the hydro-mechanical behaviour of Boom clay. This is in agreement with the analysis of water salinity effect on the values of liquid limit. 
Indeed, as mentioned before, Yukselen-Aksoy et al. (2008) showed that when the liquid limit of clays was less than about $110 \%$, the salt effect to liquid limit was not obvious; but significant effect was identified for higher liquid limit values.

Yukselen-Aksoy et al. (2008) also showed that the salinity effect on the compression index and swelling index of clays was quite low when the liquid limit with distilled water was lower than 110\%. On the contrary, Di Miao et al. (2004), Cajo and Maines (2007) showed that the water salinity had significant effect on the hydro-mechanical behavior of bentonite. Di Miao et al. (2004) also showed that the hydro-mechanical behavior of kaolinite was not influenced by the pore water salinity. These results confirm the conclusion that the content of smectite mineral is likely the main factor to be considered in investigating the pore water chemistry effects on the hydro-mechanical behaviour. Thus it is normal that a low effect of water chemistry was observed for Ess83 and no effect was identified for Ess96 because the former contains more smectite $(10 \%)$.

\section{Conclusion}

Essen site has been chosen as an alternative site in the Belgian program for nuclear waste disposal. As the host Boom clay at this site presents a pore water salinity 4-5 times higher as Boom clay at Mol, it is necessary to have an insight to the effect of water salinity on the hydromechanical behaviour of Boom clay. In the present work, the swelling behaviour, the volume change behaviour and the hydraulic conductivity were studied on intact Boom clay from Essen site with both distilled water and synthetic water. In order to be representative, the range of the total salinity considered for the synthetic water was limited to the total salinity of site water (between 5.037 and $5.578 \mathrm{~g} / \mathrm{L}$ ). The results obtained allow the following conclusions to be drawn:

(1) The liquid limit values were determined using both synthetic water and distilled water; slightly higher values were obtained in the case of synthetic water. The difference observed is believed to be negligible, in agreement with the observation of Yukselen-Aksoy et al. (2008) for low plasticity clays.

(2) The saturation or pore water replacement under the in situ stress of $2.4 \mathrm{MPa}$ did not induce significant change in soil volume for both Ess83 and Ess96.

(3) For Ess83, the oedometer modulus $E_{O d o}$, consolidation coefficient $C_{v}$ and secondary deformation coefficient $C_{a}$ are slightly different when using synthetic water and distilled water: $E_{O d o}$ and $C_{v}$ are relatively larger and $C_{a}$ is lower in the case of synthetic water. However, the pore water salinity doesn't show any effect on the relationship between the hydraulic conductivity and void ratio, as well as the relationship between the secondary consolidation coefficient $C_{a}$ and the compression index $C^{*}{ }_{c}$.

(4) For Ess96, no obvious influence of pore water salinity was identified on the hydraulic conductivity, oedometer modulus, consolidation coefficient and secondary deformation coefficient.

(5) Examination of the mineralogical composition of Ess83 and Ess96 showed that the smectite content is likely the main factor to be considered in investigating the pore water chemistry effects on the hydro-mechanical behaviour of Boom clay. As Ess83 contains more smectite (10\%), it appears normal the Ess 83 shows more effects of pore water chemistry. But on the whole, these effects are quite limited. 


\section{Acknowledgements}

ONDRAF/NIRAS (The Belgian Agency for Radioactive Waste and Enriched Fissile Materials) is gratefully acknowledged for its financial support. The first author is also grateful to the National Science Foundation of China for its support (No 50908049).

\section{References}

AFNOR, 1995. Sols : reconnaissance et essais: essai de gonflement à l'oedomètre, détermination des déformations par chargement de plusieurs éprouvettes. XP P 94-091.

AFNOR, 2005. Geotechnical investigating and testing, Laboratory testing of soils, Part 5: Incremental loading oedometer test. XP CEN ISO/TS 17892-5.

Bernier, F., Li, X.L.. and Bastiaens, W. 2007. Twenty-five years' geotechnical observation and testing in the Tertiary Boom clay formation. Géotechnique, 57(2): 229 - 237.

Bowders, J.J. and Daniel, D.E. 1986. Hydraulic conductivity of compacted clay to dilute organic chemicals. Journal of Geotechnical Engineering, 113(12):1432-1448.

Chen, J. and Anadarajah, A. 1998. Influence of pore fluid composition on volume of sediments in kaolinite suspensions. Clays and Clay Minerals, 46 (2): 145-152.

Cui, Y.J., Le, T.T., Tang, A.M., Delage, P. and Li X.L. 2009. Investigating the time dependent behavior of Boom clay under thermomechanical loading. Géotechnique, 59(4): 319-329.

De Craen, M., Wemaere, I., Labat, S. and Van Geet, M. 2006. Geochemical analyses of Boom Clay pore water and underlying aquifers in the Essen-1 borehole. SCK $\bullet$ CEN external report ( REPORT SCK•CEN-ER-19), Belgium.

Delage, P., Le, T.T., Tang, A.M., Cui, Y.J., and Li X.L. 2007. Suction effects in deep Boom clay samples. Géotechnique, 57(2): 239-244.

Di Maio, C., 1996. Exposure of bentonite to salt solution: osmotic and mechanical effects. Géotechnique, 46 (4): 695-707.

Di Maio, C., Santoli, L. and Schiavone, P. 2004. Volume change behavior of clays: the influence of mineral composition, pore fluid composition and stress state. Mechanics of Materials, 36: 435-451.

Gajo, A. and Maines, M. 2007. Mechanical effects of aqueous solutions of inorganic acids and bases on a natural active clay. Géotechnique, 57(8): 687-699.

Kaya, A. and Fang, H.Y. 2000. The effects of organic fluids on physicochemical parameters of fine-grained soils. Canadian Geotechnical Journal, 37: 943-950.

Mesri, G., Kwan, L.D.O., and Feng, W.T. 1994. Settlement of embankment on soft clays. Proc. Of settlement 94, ASCE Geotechnical Special Publication, 40: 8-56.

Ören, A.H. and Kaya, A., 2003. Some engineering aspects of homoionized mixed clay minerals. Environmental Monitoring and Assessment, 84: 85-98.

Smiles, D.E., 2008. Effects of solutes on clay- water interactions: Some comments. Applied Clay Science, 42:158-162.

Sridharan, A. and Prakash, K. 1999. Influence of clay mineralogy and pore medium chemistry on clay sediment formation. Canadian Geotechnical Journal, 36: 961-966.

Sridharan, A., El-Shafei, A. and Miura, N. 2002. Mechanisms controlling the undrained strength behavior of remolded Ariake marine clays. Marine Georesources and Geotechnology 20:21-50. 
Waddah, S. A., Mohammed, S. A. and Khalid, A. A. 1997. On the physicochemical aspects of compacted clay compressibility. Canadian Geotechnical Journal. 34(4): 551-559.

Wakim, J. 2005. Influence des solutions aqueuses sur le comportement mecanique des roches argileuses, These de l'Ecole Nationale Supérieure des Mines de Paris, pp.154.

Yukselen-Aksoy, Y., Kaya A. and Ören, A. H. 2008. Seawater effect on consistency limits and compressibility characteristics of clays. Engineering Geology, 102:54-61. 


\section{List of Tables}

Table 1. Pore water salinity of Boom clay

Table 2. Geotechnical properties the two soil cores studied

Table 3. Mineralogical composition obtained by X-ray diffraction

\section{List of Figures}

Figure 1. Locations of Mol site and Essen site (De Craen et al., 2006)

Figure 2. Particle size distribution curves

Figure 3. Results from oedometer test Ess83Odo3

Figure 4. e- $\log \sigma$ 'v curve from test Ess83Odo3

Figure 5. Determination of parameters from test Ess83Odo3

Figure 6. e- $\log \sigma^{\prime} v$ curves from all tests on two different cores and using two different pore water chemistries

Figure 7. Hydraulic conductivity versus void ratio for Ess83 and Ess96

Figure 8. Oedometer modulus versus void ratio for Ess83 and Ess96

Figure 9. Consolidation coefficient versus void ratio for Ess83 and Ess96

Figure 10. Secondary consolidation coefficient versus void ratio for Ess 83 and Ess 96

Figure 11. Secondary consolidation coefficient versus compression index for Ess83 and Ess96 
Table 1. Pore water salinity of Boom clay

\begin{tabular}{l|l|l|l}
\hline \multirow{2}{*}{ Salt } & Ess83 & Ess96 & Mol \\
\cline { 2 - 4 } & \multicolumn{3}{|c}{$10^{-3} \mathrm{Mol} / \mathrm{L}$} \\
\hline \hline $\mathrm{NaHCO} 3$ & 7.16 & 7.16 & 13.93 \\
\hline $\mathrm{Na2SO} 4$ & 5.23 & 5.81 & 0.002 \\
\hline $\mathrm{KCl}$ & 0.61 & 0.61 & 0.34 \\
\hline $\mathrm{CaCl} 2.2 \mathrm{H} 2 \mathrm{O}$ & 0.52 & 0.57 & \\
\hline $\mathrm{MgCl} 2.6 \mathrm{H} 2 \mathrm{O}$ & 1.44 & 1.60 & 0.11 \\
\hline $\mathrm{NaCl}$ & 54.7 & 61.6 & 0.17 \\
\hline $\mathrm{H} 3 \mathrm{BO} 3$ & & & 0.70 \\
\hline $\mathrm{NaF}$ & & & 0.26 \\
\hline $\mathrm{CaCO3}$ & & & 0.05 \\
\hline $\mathrm{Na}+$ & 72.32 & 80.38 & 14.104 \\
\hline $\begin{array}{l}\mathrm{Total} \text { salinity } \\
\text { (g/L) }\end{array}$ & 5.037 & 5.578 & 1.286 \\
\hline \hline
\end{tabular}


Table 2. Geotechnical properties the two soil cores studied

\begin{tabular}{l|l|l|l|l|l|l|l|l|l|l}
\hline \hline Core & Depth $(\mathrm{m})$ & Member & $\mathrm{G}_{\mathrm{s}}$ & $\begin{array}{l}w_{L} \\
(\%)\end{array}$ & $\begin{array}{l}w_{p} \\
(\%)\end{array}$ & $\begin{array}{l}I_{p} \\
(\%)\end{array}$ & $\mathrm{w}$ & $\mathrm{e}_{0}$ & VBS & $\begin{array}{l}\text { Carbonate } \\
\text { content }(\mathrm{g} / \mathrm{kg})\end{array}$ \\
\hline \hline Ess83 & $226.65-227.65$ & Putte & 2.64 & $67.2^{*}$ & 33 & 37 & 27.2 & 0.730 & 6.67 & 7.6 \\
\hline Ess96 & $239.62-240.62$ & Terhagen & 2.68 & $67.1^{*}$ & 33 & 36 & 26.5 & 0.715 & 6.20 & 2.4 \\
\hline
\end{tabular}

* Testing with distilled water

Table 3. Mineralogical composition obtained by X-ray diffraction

\begin{tabular}{l|l|l|l||l|l|l|l|l}
\hline \hline \multirow{2}{*}{ Core } & \multicolumn{3}{|c|}{ Soil studied (\%) } & \multicolumn{5}{c}{ Clay fraction (\%) } \\
\cline { 2 - 10 } & Quartz & $\begin{array}{l}\text { Illite } \\
\text { Mica }\end{array}$ & Kaolinite & Chlorite & Kaolinite & Illite & Smectite & Ill/Smect \\
\hline \hline Ess83 & 60 & 10 & 30 & 5 & 35 & 20 & 20 & 20 \\
\hline Ess96 & 70 & 10 & 20 & 5 & 35 & 20 & 10 & 30 \\
\hline \hline
\end{tabular}

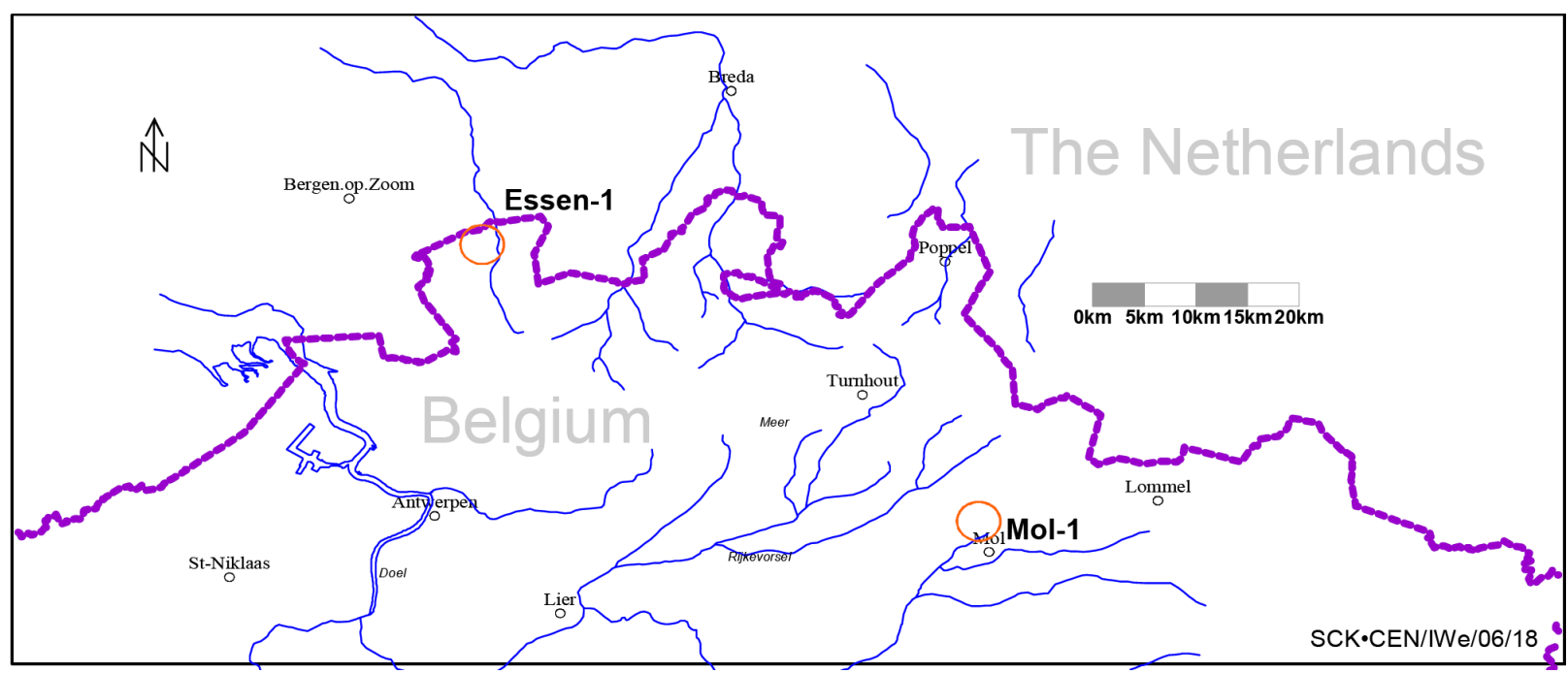

Figure 1. Locations of Mol site and Essen site (De Craen et al., 2006) 


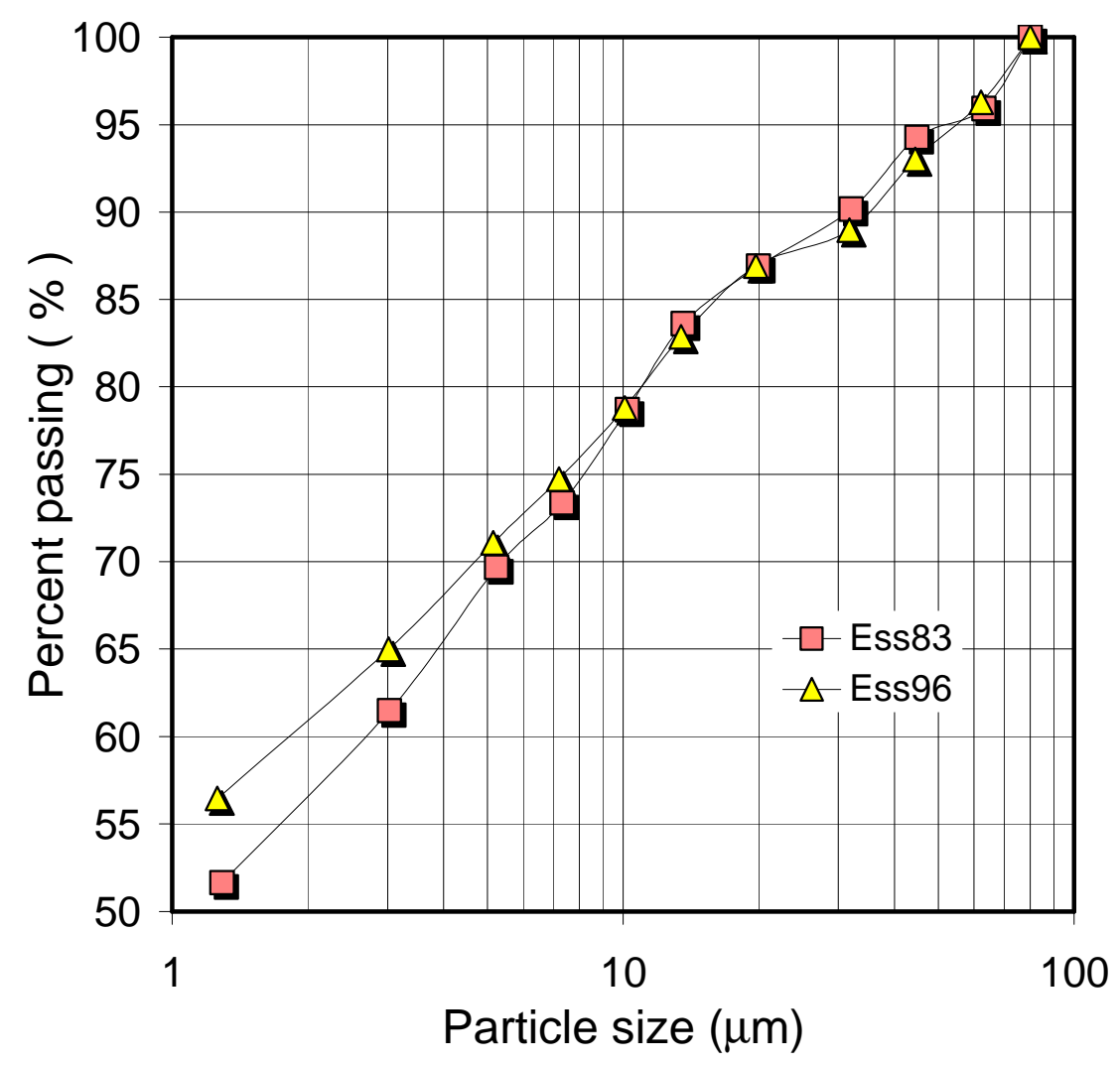

Figure 2. Particle size distribution curves 

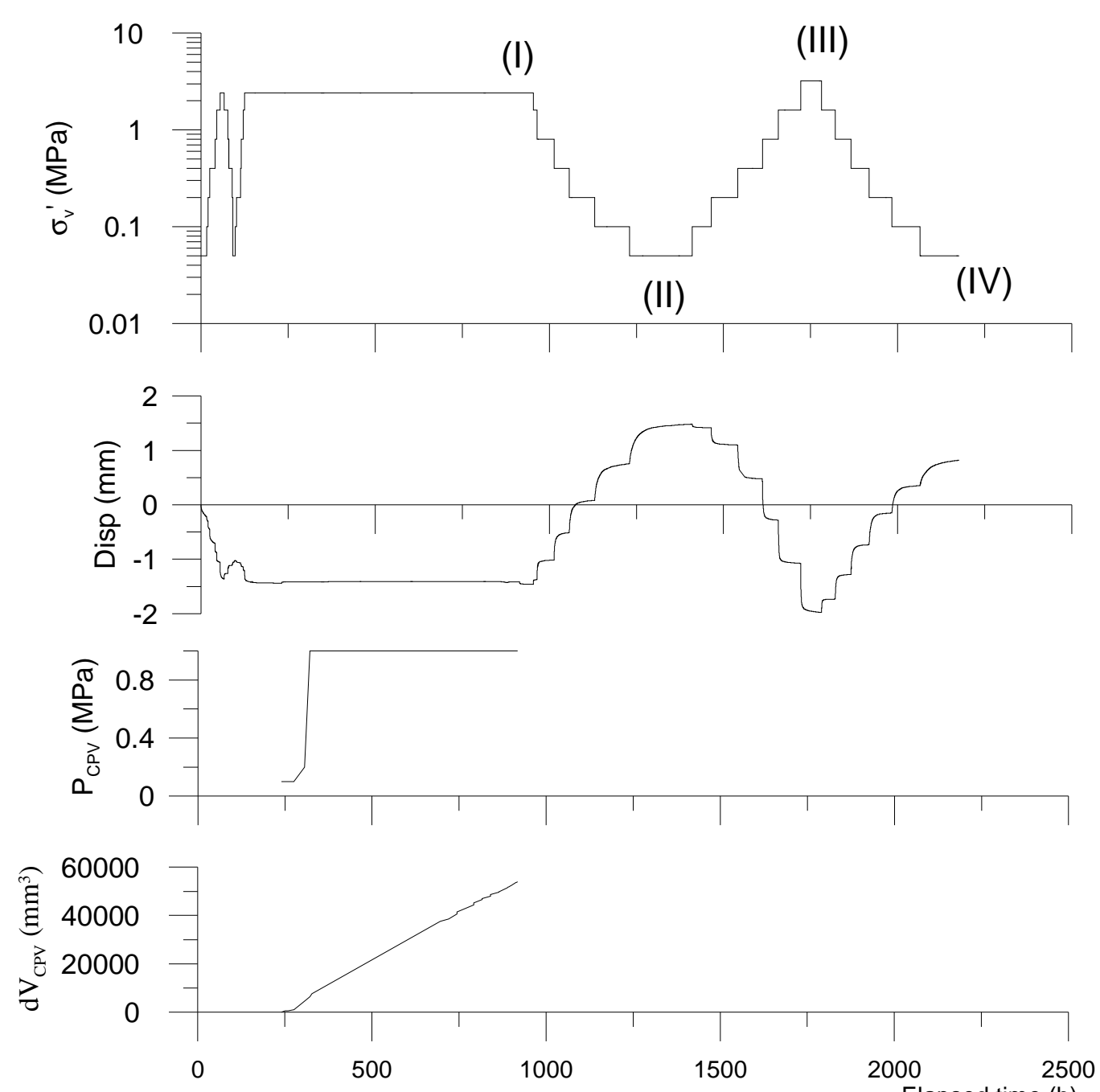

Figure 3. Results from oedometer test Ess83Odo3 


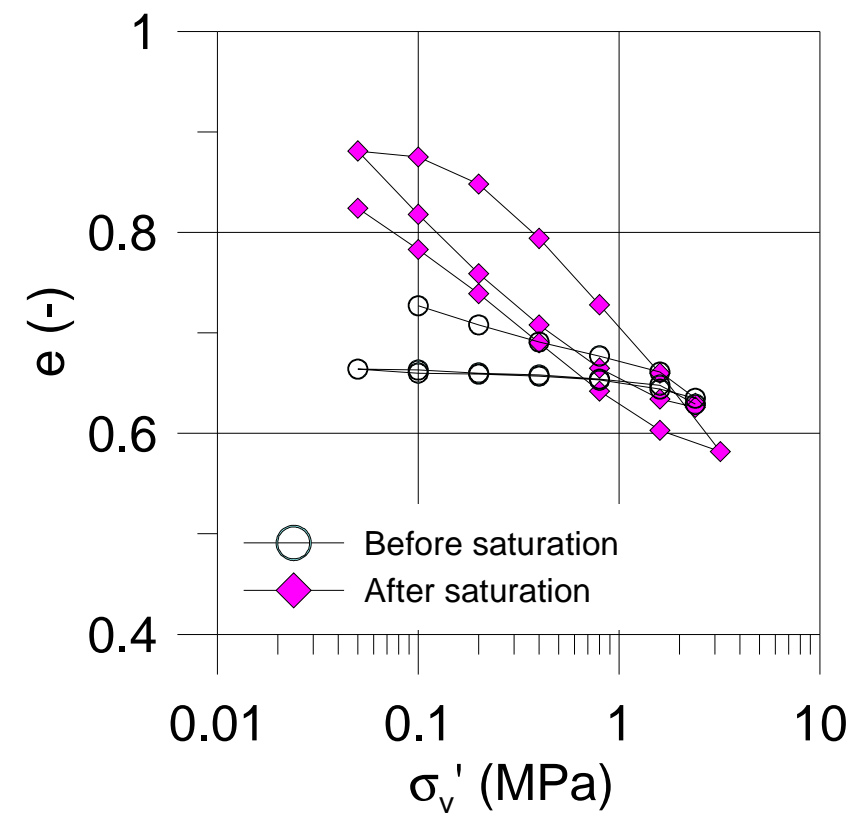

Figure 4. e- $\log \sigma$ 'v curve from test Ess83Odo3 


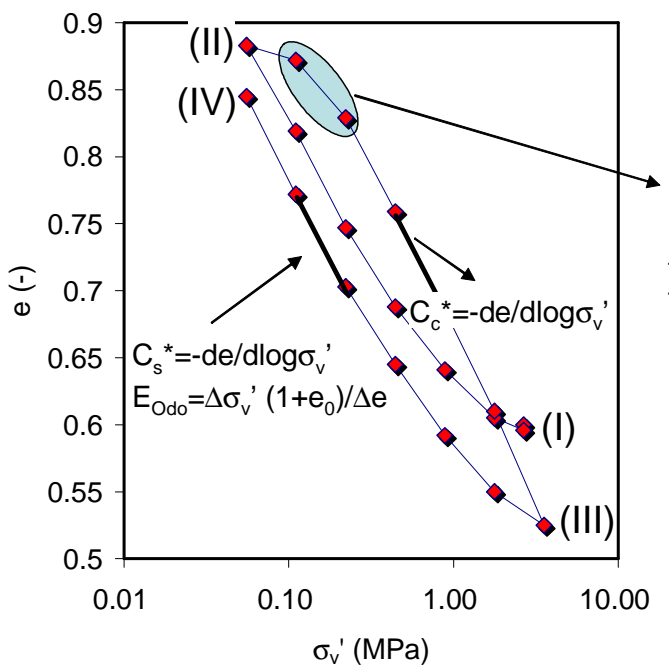

(a)

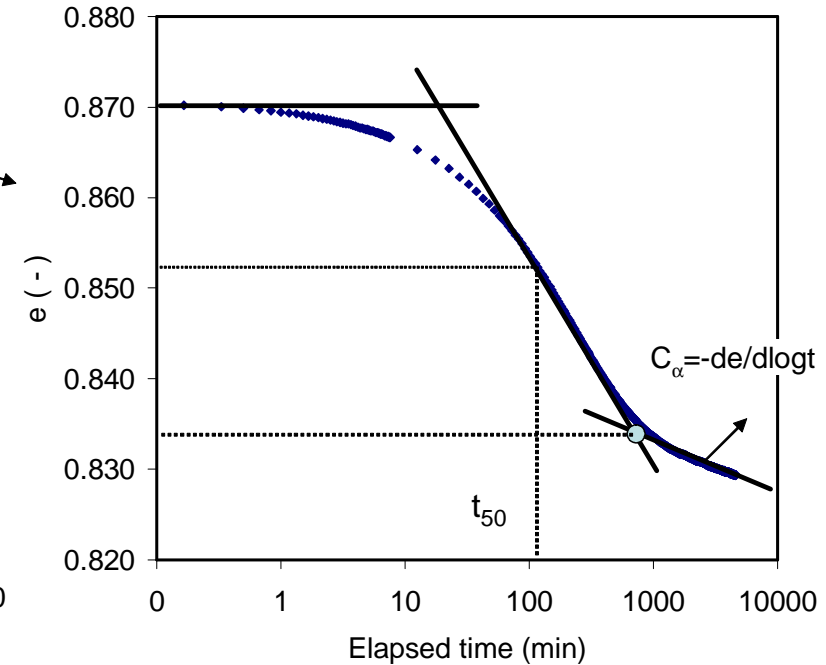

(b)

Figure 5. Determination of parameters from test Ess83Odo3 

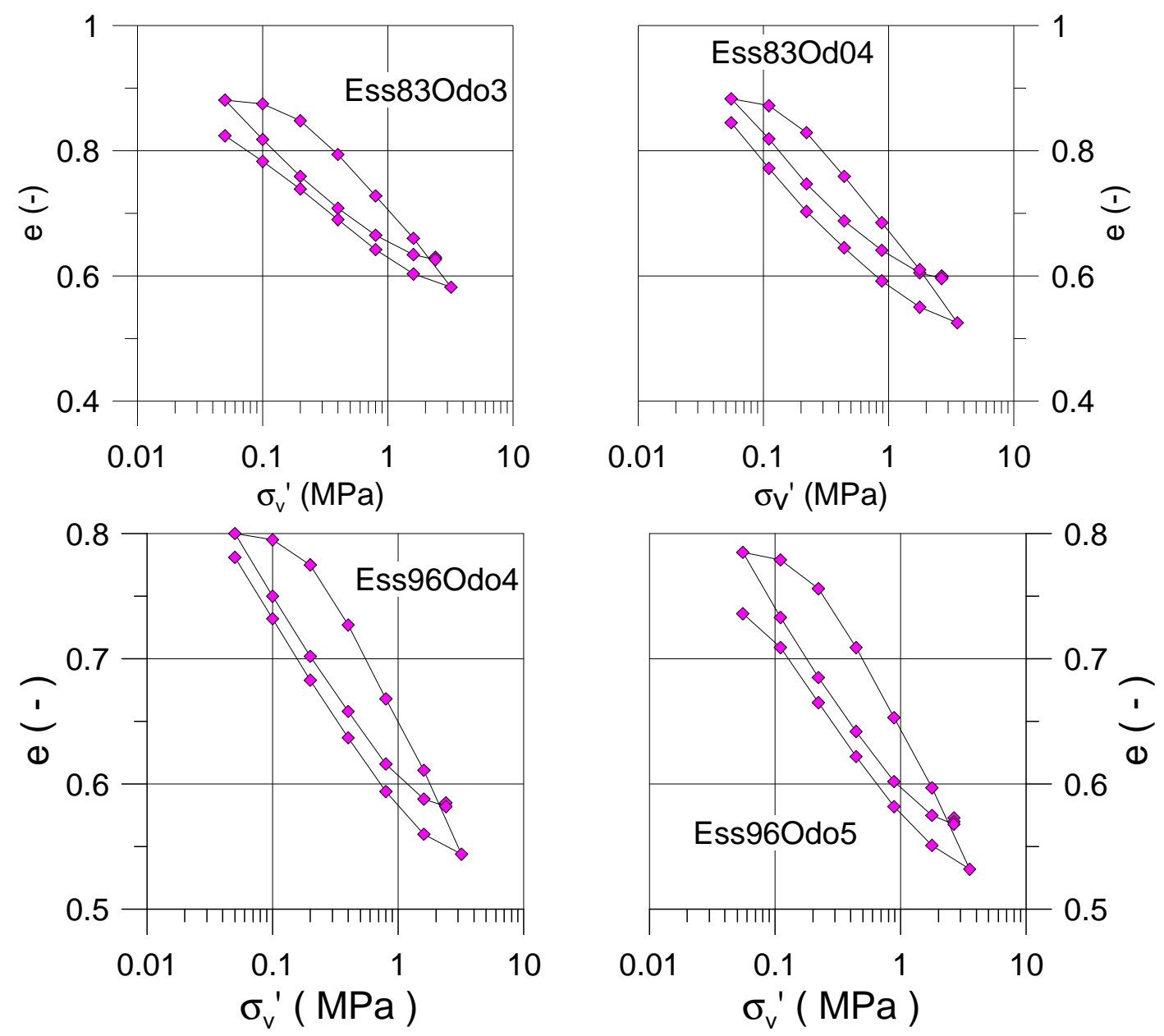

Figure 6. e- $\log \sigma^{\prime} v$ curves from all tests on two different cores and using two different pore water chemistries 

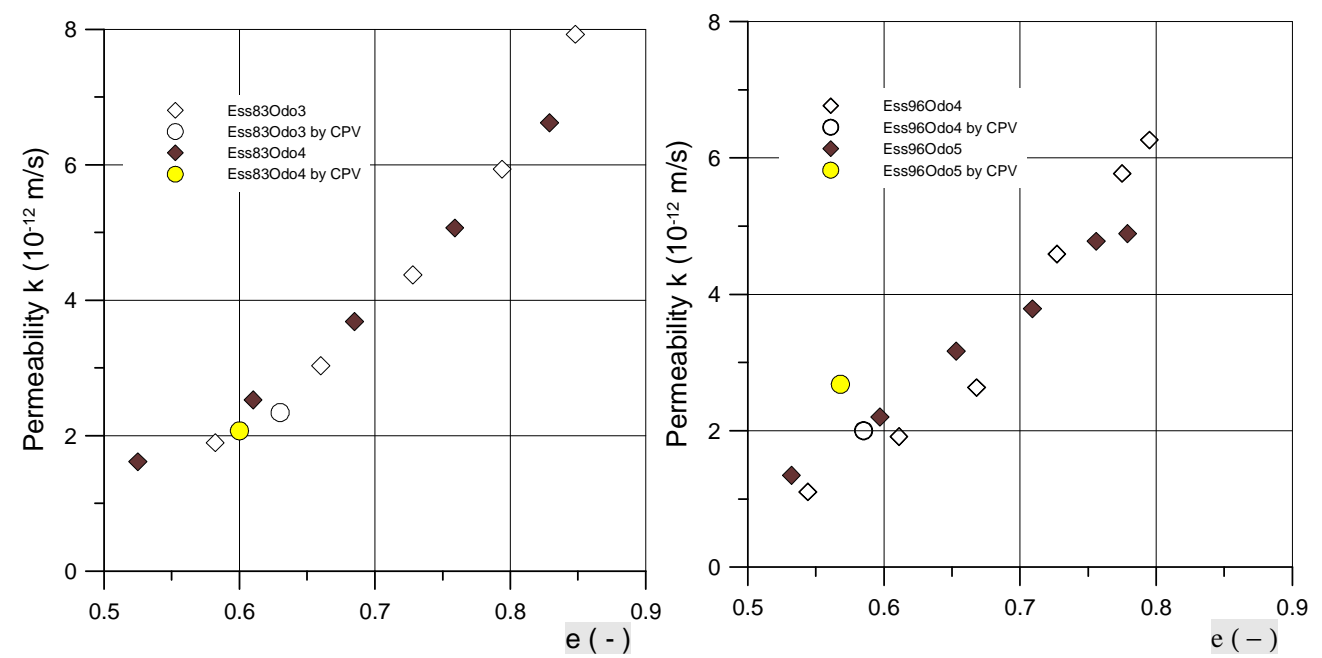

Figure 7. Hydraulic conductivity versus void ratio for Ess83 and Ess96 

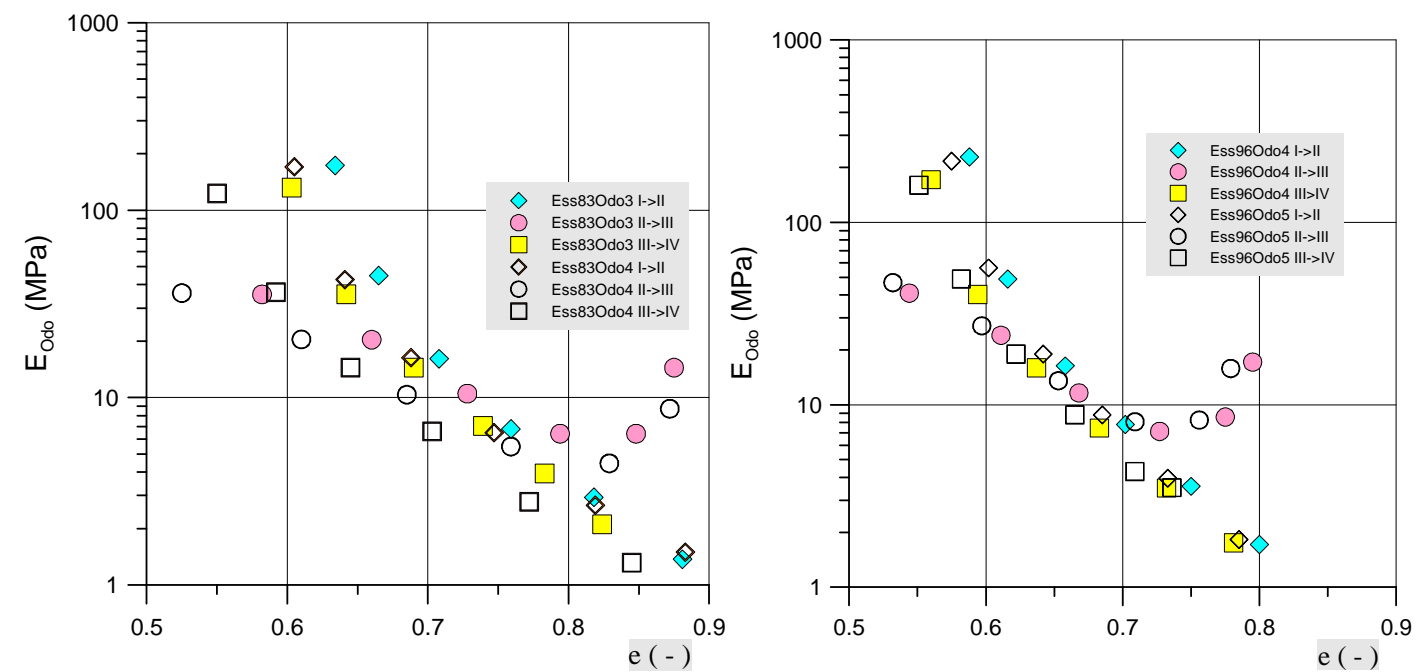

Figure 8. Oedometer modulus versus void ratio for Ess83 and Ess96 

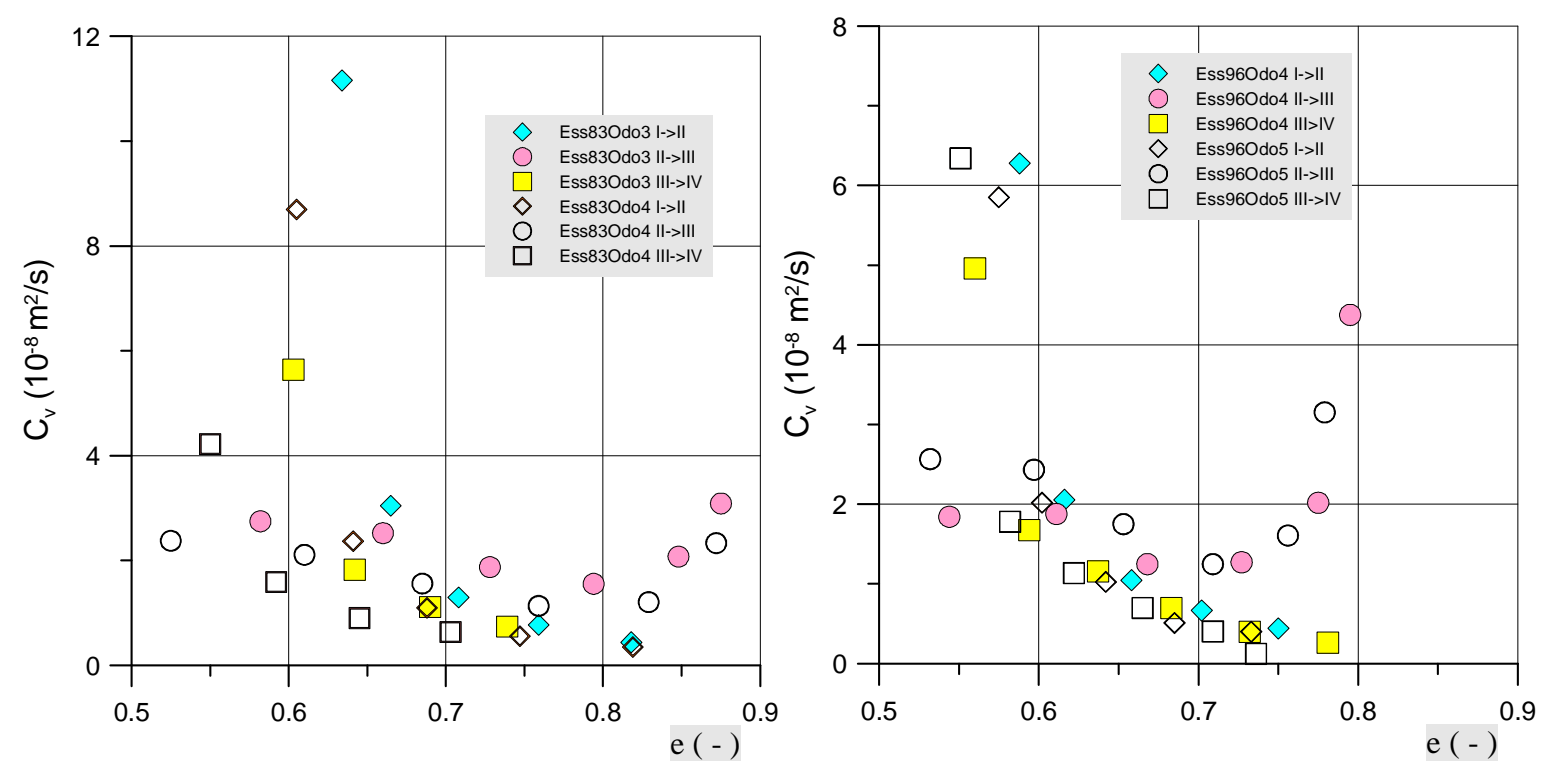

Figure 9. Consolidation coefficient versus void ratio for Ess83 and Ess96 

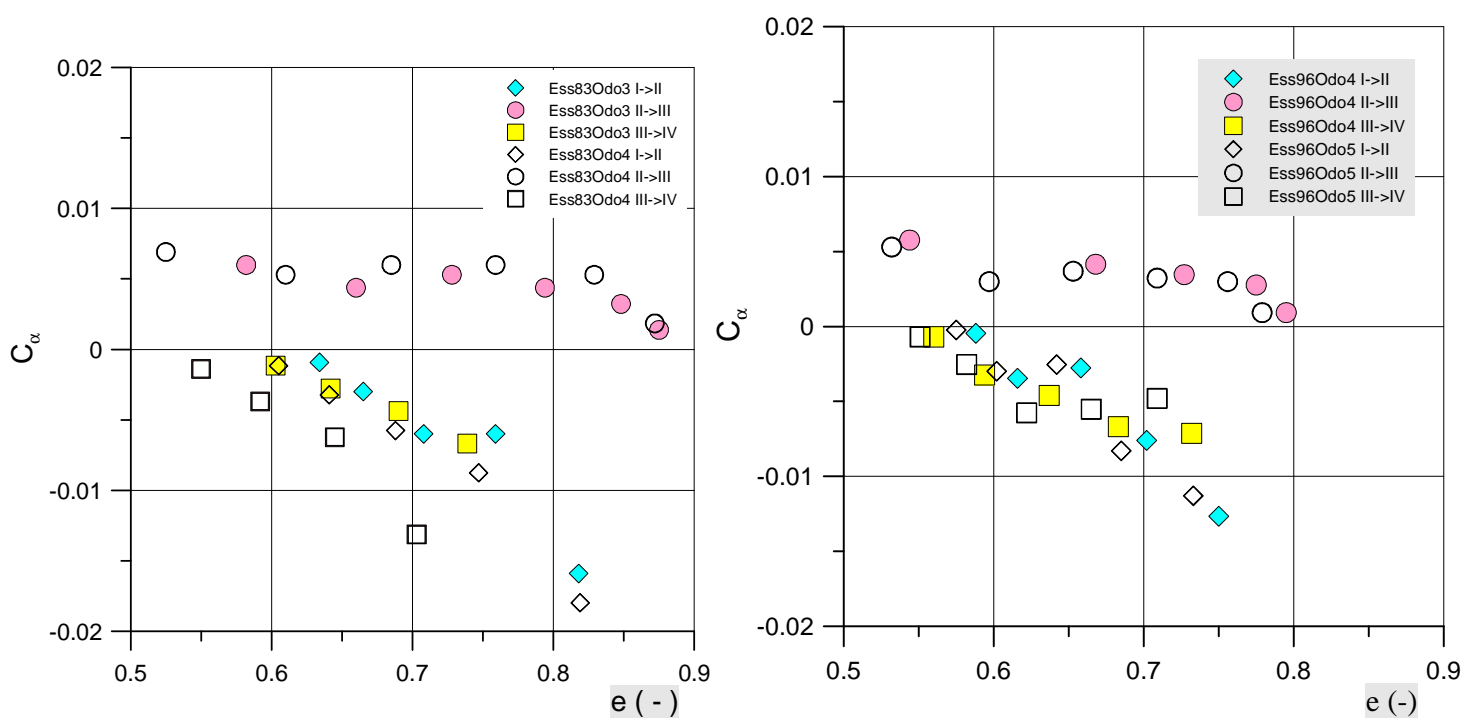

Figure 10. Secondary consolidation coefficient versus void ratio for Ess 83 and Ess 96 

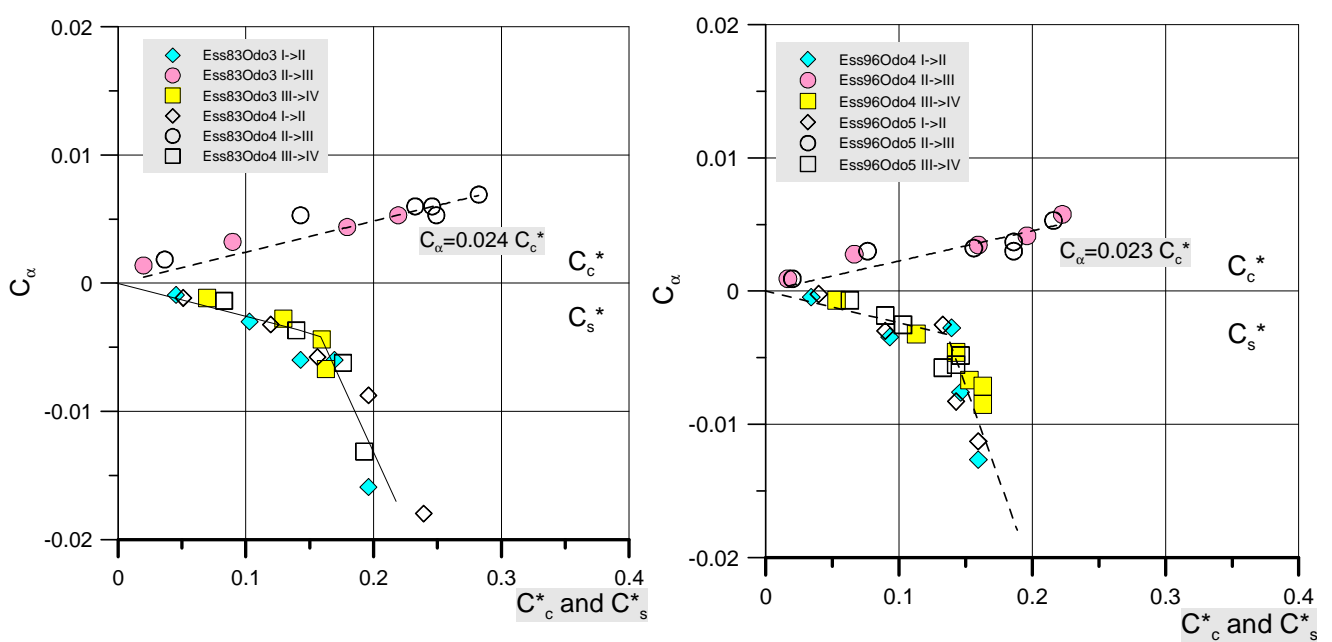

Figure 11. Secondary consolidation coefficient versus compression index for Ess 83 and Ess96 